\title{
Analysis Predictors of the Outcome of Adjuvant of Hormone Therapy on Estrogen Receptor-positive Breast Cancer in Indonesia
}

\author{
Hardisman Dasman ${ }^{1} *$ D, Wirsma Arif Harahap ${ }^{2}$, Daan Khambri ${ }^{3}$ \\ ${ }^{1}$ Department of Public Health and Community Medicine, Faculty of Medicine, Andalas University, Padang, Indonesia; \\ ${ }^{2}$ Department of Surgery, Division of Surgical Oncology, Faculty of Medicine, Andalas University, M Djamil General Hospital, \\ Padang, Indonesia; ${ }^{3}$ Department of Surgery, Division of Surgical Oncology, Faculty of Medicine, Andalas University, M Djamil \\ General Hospital, Padang, Indonesia
}

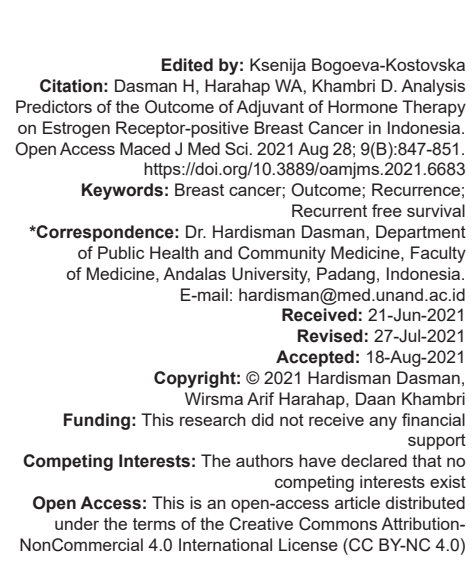

Introduction

Breast cancer is the most prevalent cancer among women in the world, and also one of the main causes of death [1], [2], [3]. Breast cancer is also the most prevalent in women in Indonesia, which is recorded about $30.8 \%$, and also the most common cancer-related mortality cause among women in the country (WHO, 2020).

The cancers can be classified into molecular subtypes, including luminal A, luminal $B$, human epidermal growth factor receptor 2 (HER2+), and triple-negative (TN) [4], [5]. Luminal A breast cancer is a cancer type with hormone-receptor positive, either estrogen receptor (ER) or progesterone receptor (PR) positive, HER2 negative, and has low level of the protein Ki-67.The luminal A type is a low-grade and tend to grow slowly and have the best prognosis. Luminal B breast cancer is a cancar type hormonereceptor positive and either HER2 positive or negative with high level of Ki-67. Luminal B cancers grow slightly faster than luminal A cancers. TN or basal-like breast cancer is hormone-receptor (ER and $P R$ ) negative and HER2 negative. HER2-enriched non-luminal is ER and PR negative and HER2 positive. HER2-enriched cancers tend to grow faster than luminal cancers and can have a worse prognosis. However, HER2 cancers are more successfully treated with targeted therapy for HER2 protein. Clinical courses, patterns of metastasis, and outcome and prognosis may also vary among these subgroups [4], [5]. The recurrence mostly happens during the first 5 years after treatment among all subtypes. However, late recurrence may also occur, such as in the luminal subtype with HER2 negative and PR-positive [6]. The recurrence may increase in cancer with high staging and HER2 positive, and inverse with the ER and PR status [7].

Some breast cancers are growing sensitive to female body hormones, estrogen and progesterone, in which breast cancer cells have receptors that can interact with those hormones in the circulation. From 
the expression of the hormone receptors, breast cancer can be ER positive $(E R+)$ and progesterone positive $(\mathrm{PR}+)$, or ER- and PR-. The ER+ is a type of breast cancer that has receptors that are stimulated to grow by estrogen hormone, and PR+ is a type of breast cancer that has PR and sensitive to progesterone to grow [8].

Treatment of ER+ type is with anti-estrogen hormone therapy can block the growth of the cancer cells. Few groups of hormonal therapy may be used, including selective estrogen-receptor response modulators (such as tamoxifen and toremifene), aromatase inhibitors that stop the production of estrogen by blocking the enzyme aromatase (such as anastrozole, exemestane, and letrozole), estrogen-receptor downregulators that block the effects of estrogen in breast tissue (such as fulvestrant), and luteinizing hormone-releasing hormone agents that stop the ovaries from producing estrogen (such as goserelin and leuprolide) [8]. Many studies suggested that the patients who have adjuvant hormone therapy had a better outcome, with low recurrence [9], [10].

Outcome and recurrence of breast cancer associate with the cancer clinicopathology features and treatment [11]. The existing publications on breast cancer recurrence were limited and heterogeneous [12]. The increasing of invasive cancer tended to have a higher risk of recurrence [13]. Lafourcade et al. [14] also reported that low survival of breast cancer was associated with high grade of the tumor, large size, and negative estrogen, and PRs. However, the result may vary among studies [11], [15]. Specifically, the response to hormone therapy in ER+ breast cancer also varied among other parameters, such as in PR- the outcome was low [16].

Due to variation of studies on the possible outcome and inadequate report in the Indonesian context, in this study, we had to explore predictors of the outcome of hormone therapy in ER+ breast cancer in the country, by considering other clinicopathology parameters.

\section{Materials and Methods}

\section{Study design and research sample}

This research was quantitative research with a cross-sectional prospective design. The subjects of the study were breast cancer patients with ER+ who had adjuvant hormone therapy in 2017-2018. The initial clinicopathology data were collected during treatment which were recorded in the medical record.

The follow-up has been conducted with 2 years of the treatment to assess the outcome or event of recurrence of the disease. The 2 years of follow-up were very feasible to be conducted due to the relatively short period. Within 2 years after treatment, breast cancer is more likely to have an initial recurrence.

The subjects of the study were collected from three hospitals in Padang City, West Sumatera Province of Indonesia, which were M Djamil General Hospital, YARSI Hospital, and Ropanasuri Surgical Hospital, which had experts and facilities for definitive treatment for breast cancer. Within 2 years of follow-up, 219 cases were eligible for the study with completed clinicopathology data. All patients in the study were funded under the national health insurance scheme for their treatment.

\section{Operational definitions}

The variables of this study included age, cancer stage, lymphovascular invasion (LVI) status, PR Expression, HER2 status, and molecular subtype as independent variables. For bivariate analysis, all those variables were measured in categorical data.

The dependent variable was recurrencefree survival (RFS) for measuring the outcome. The recurrence was measured by any signs in clinical examination, which was performed by the clinician expert within 2 years of follow-up. The recurrence was included local or regional and distant recurrence. Local recurrence was cancer that was back in the same place it first started, while regional recurrence means the cancer was back in the lymph nodes near the place it first started, and distant recurrence means the cancer was back and growing in another part of the body, such as lungs, liver, bone, or brain. Cancer survival means that there were no signs of any recurrence either local or regional and distance during the follow-up.

\section{Data collection technique and analysis}

The clinicopathology data including age, cancer stage, LVI status, PR, HER2, and molecular subtype were collected during the patients' treatment by the clinicians who were also part of the research team. The data were written and available in the medical record. Within 2 years, the clinicians and the researchers followed up on the patient's condition. The followed-up mostly focus on any signs of recurrence, either local or regional and distance.

Univariate, bivariate, and multivariate analyses were performed to answer the research questions and to draw a conclusion. Univariate analysis was to see the proportion of cases in each pathology parameter and the outcome within 2 years. Bivariate analysis by conducting Chi-square with correction and Fisher's exact test was done to examine the association of clinicopathology to the outcome. Later logistic regression was performed to determine the dominant factor associated with the survival outcome. 
Mediation path analysis was performed to determine the estimated effect of a predictor on the level of RFS. The mediation analysis also explores any direct and indirect effect of other parameters through mediation predictor, and as well as see the visualization of association of predictors with RFS.

\section{Results}

The samples of the study were mostly with age $<55$ years old (pre-menopause) (63.5\%). The clinicopathology was majority invasive non-specific subtype (51.5\%), LVI negative (-) $(84.0 \%)$, PR positive (+) $(82.2 \%)$, and HER2 negative $(70.3 \%)$. Meanwhile, the cancer staging was range from Stage I to IV, with equally distributed Stage IIA (27.4\%), IIB (23.3\%), and IIIB $(27.4 \%)$ (Table 1).

Table 1: Characteristics of breast cancer in the study

\begin{tabular}{llll}
\hline Characteristics & Category & $\mathrm{f}(\mathrm{n}=219)$ & $\%$ \\
\hline Age & $<55$ & 139 & 63.5 \\
& $>55$ & 80 & 36.5 \\
Histopathology Subtype & Invasive non-specific type & 112 & 51.1 \\
& Invasive ductal & 44 & 20.1 \\
& Invasive lobular & 36 & 16.4 \\
& Invasive mucinous & 13 & 5.9 \\
& Mix type & 4 & 1.8 \\
& Others & 10 & 4.6 \\
LVI & Negative & 184 & 84.0 \\
& Positive & 35 & 16.0 \\
PR & Negative & 39 & 17.8 \\
& Positive & 180 & 82.2 \\
HER2 & Negative & 154 & 70.3 \\
& Positive & 65 & 29.7 \\
Molecular Subtype & Luminal A & 80 & 36.5 \\
& Luminal B & 139 & 63.5 \\
Stage & I & 8 & 3.7 \\
& IIA & 60 & 27.4 \\
& IIB & 51 & 23.3 \\
& IIIA & 27 & 12.3 \\
& IIIB & 60 & 27.4 \\
& IIIC & 2 & 0.9 \\
& IV & 11 & 5.0 \\
\hline LVI: Lymphovascular invasion, PR: & Progesterone receptor, HER2: Human epidermal growth factor \\
receptor 2. & & &
\end{tabular}

Breast cancer RFS was $91.3 \%$ within 2 years of follow-up after hormonal therapy, with a recurrent rate of $8.7 \%$. Out of 19 cases of recurrence, the majority of them $(68.4 \%)$ were local recurrence (Table 2$)$.

Table 2: Outcome therapy

\begin{tabular}{lll}
\hline Outcome & $\mathrm{f}$ & $\%$ \\
\hline RFS $(\mathrm{n}=219)$ & 200 & \\
Yes (survive) & 19 & 81.3 \\
$\quad$ No (recurrent) & 13 & \\
Recurrent $(n=19)$ & 6 & 68.4 \\
$\quad$ Local & & 31.6 \\
$\quad$ Distance & &
\end{tabular}

Breast cancer RFS within 2 years of adjuvant hormone therapy was slightly lower in age $<50(89.2 \%)$ than $>50$ years old $(95.0 \%)$, but it was not statistically significant $(p=0.143)$. The cancer RFS was comparable between LVI status negative $(91.3 \%)$ and positive $(91.4 \%)(p=0.981)$, PR negative $(92.3 \%)$ and positive $(91.1 \%)(p=0.810)$, and HER2 negative $(90.9 \%)$ and positive $(92.3 \%)(p=0737)$. According to the molecular subtype, the RFS was better in luminal A (96.3\%) than luminal $B(88.5 \%)(p=0.045)$. The cancer RFS was also better gradually in the lower stage $(p=0.001)$ (Table 3$)$.

Table 3: Bivariate analysis association of predictors with the outcome

\begin{tabular}{lllll}
\hline Variable & Category & Survive (f, \%) & Recurrence (f, \%) & p-value \\
\hline Age & $<55$ & $124(89.2)$ & $15(10.8)$ & 0.143 \\
& $>55$ & $76(95.0)$ & $4(5.0)$ & \\
LVI & Negative & $168(91.3)$ & $16(8.7)$ & 0.981 \\
& Positive & $32(91.4)$ & $3(8.6)$ & 0.810 \\
PR & Negative & $36(92.3)$ & $3(7.7)$ & \\
& Positive & $164(91.1)$ & $16(8.9)$ & 0.737 \\
HER2 & Negative & $140(90.9)$ & $14(9.1)$ & 0.045 \\
& Positive & $60(92.3)$ & $5(7.7)$ & 0.001 \\
Molecular Type & Luminal A & $77(96.3)$ & $3(3.8)$ & \\
Stage & Luminal B & $123(88.5)$ & $16(11.5)$ & \\
& I & $8(100.0)$ & $0(0.0)$ & \\
& II & $106(95.5)$ & $5(4.5)$ & $8(9.0)$ \\
& III & $81(91.0)$ & $6(54.5)$ & \\
LVI: Lymphovascular invasion, PR: Progesterone receptor, HER2: Human epidermal \\
growth factor receptor 2.
\end{tabular}

Regression multivariate analysis shows that the staging was the dominant predictor of the outcome $(p=0.001)$. The cancer staging positively associates with the RFS with OR $=4.271(\operatorname{Exp}[\mathrm{B}]=1.937-9.417)$, which lower staging cancer tended to have better survival outcomes. Overall, all predictors that have been analyzed affected the RFS $22.1 \%$ (R-square) (Table 4).

Table 4: Multivariate analysis of determinant predictor to the outcome

\begin{tabular}{lllll}
\hline Predictor & $\mathrm{B}$ & $\mathrm{p}$ & $\operatorname{Exp}(\mathrm{B})(95 \%, \mathrm{Cl})$ & R-square \\
\hline Age & -0.909 & 0.136 & $(\mathrm{NA})$ & 0.221 \\
Molecular subtype & 1.048 & 0.117 & (NA) & \\
Staging & 1.452 & 0.001 & $4.271(1.937-9417)$ & \\
\hline
\end{tabular}

Further analysis in exploring the effect of other predictors on the level of recurrence was examined by mediation analysis. The study found that there was no statistically significant association of age, LVI, PR, and HER2 status with RFS through cancer stage mediation $(p>0.005)$. The study also found that molecular subtype positively associates with RFS ( $r=16.7 \%)$, which means Category 1 (luminal A) had a better outcome than luminal $B(p=0.006)$ (Table 5). The completed model is seen in Figure 1.

Table 5: Total effect through cancer stage mediation

\begin{tabular}{lll}
\hline Predictor & Estimated Effect $(95 \% \mathrm{Cl})$ & p-value \\
\hline Age-(stage)->Recurrence & $-0.083(-0.193-0.027$ & 0.140 \\
LVI-(stage)->Recurrence & $0.037(-0.105-0.180)$ & 0.609 \\
PR-(stage)->Recurrence & $0.018(-0.118-0.154)$ & 0.798 \\
HER2-(stage)->Recurrence & $-0.110(-0.241-0.021)$ & 0.100 \\
Mol. Subtype -(stage)->Recurrence & $0.167(0.047-0.288)$ & 0.006 \\
\hline LVI: Lymphovascular invasion, PR: Progesterone receptor, HER2: Human epidermal growth factor
\end{tabular}
receptor 2 .

\section{Discussion}

Breast cancer RFS was $91.3 \%$ within 2 years of follow-up after hormonal therapy, with a recurrent rate of $8.7 \%$. Out of 19 cases of recurrence, the majority of them $(68.4 \%)$ were local recurrence. This study revealed that the RFS of breast cancer after adjuvant hormone therapy was relatively better than the overall 


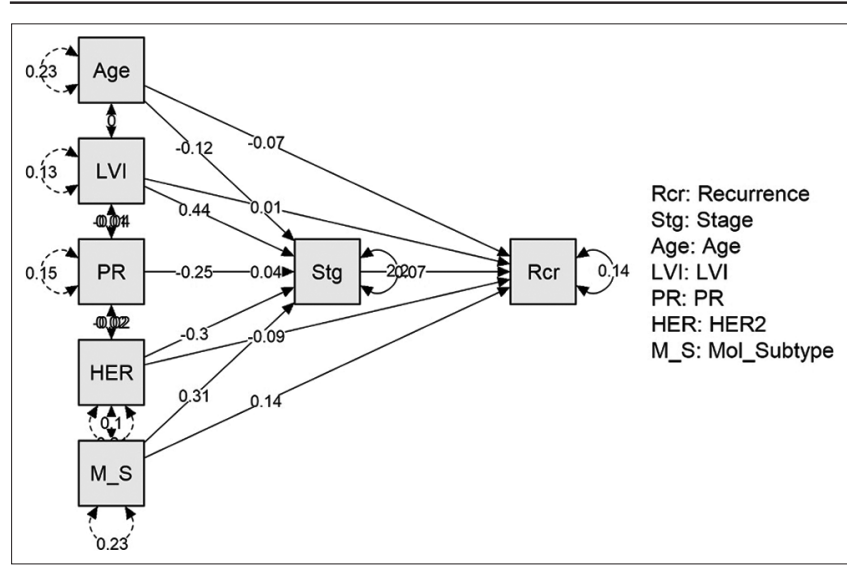

Figure 1: Mediation model of effect predictor to breast cancer recurrence

RFS of breast cancer in other studies. A meta-analysis study found that the recurrence rate of breast cancer was $17.2 \%$ on average [15]. The hazard of recurrence within 5 years of therapy was $10.4 \%$ annually, with the highest in the $1^{\text {st }}$ and the $2^{\text {nd }}$ year $(15.2 \%)$ [17]. Our finding suggests that hormonal therapy decreases the recurrence rate. Moreover, overall breast cancer tended to have predominantly distant recurrence [18], [19]. By contrast, our study found that breast cancer with hormonal therapy mostly has a local recurrence. The finding implies that hormonal therapy had benefits for both recurrent rate and the level of recurrence.

Breast cancer RFS within 2 years of adjuvant hormone therapy was slightly lower in age $<50(89.2 \%)$ than $>50$ years old $(95.0 \%)$, but it was not statistically significant $(p=0.143)$. This can be an effect of the activity of hormone physiology, in which women at younger age normally have more estrogen production than the menopause age. The effect of hormone therapy as antiestrogen might be slightly lower despite not being statistically significant. This finding is supported by others studies, which reported that the risk of recurrence is higher at a young age [20], and needs more aggressive therapy [21].

The breast cancer stage associates with the RFS, that the lower stage cancer has a better outcome $(p=0.001)$. The cancer stage is also the dominant predictor to the hormone therapy outcome with $\mathrm{OR}=4.271(\operatorname{Exp}[\mathrm{B}]=1.937-9.417)$. Low stage of cancer is most likely to have little tumor size and less lymph node involved, which have a better result of definitive therapy and low recurrence. The finding supports existing study in overall breast cancer outcome, that the cancer stage is one of the important determinants to survival [7].

According to the molecular subtype, the RFS was better in luminal A $(96.3 \%)$ than luminal B $(88.5 \%)$ $(p=0.045)$. Mediation path analysis also shows that molecular subtype positively associates with RFS ( $r=$ $16.7 \%$ ), which means luminal A most also likely to have a better outcome of RFS, especially mediated by the lower stage. This finding is consistent with other studies in overall cases of breast cancer that reported luminal $A$ has low early recurrence [22]. Physiologically luminal A breast cancer has slower growth than the others [4], [5], and hormone therapy does not affect other parameters for classified into molecular subtype.

\section{Conclusion}

Breast cancer with $\mathrm{ER}+$, which had hormone therapy, relatively has a better RFS and low recurrent rate, and as well as low risk to have a distant recurrence. The cancer stage is the main predictor of RFS, which the lower stage predominantly has a better hormone therapy outcome. Breast cancer with luminal A subtype is most likely to have a better outcome, especially mediated by the lower stage.

\section{Author Declaration of Contribution}

All authors (HD, WAH, and DK) equally contributed to developing the research, and for the final revision of the article. WAH was the main responsible for collecting the data, and HD was responsible for data analysis and initial drafting of the manuscript.

\section{Acknowledgments}

The author would like to thank all clinicians and nurses who helped to collect and recording the necessary data in the breast cancer database. The authors also thank Wiwin Susilawati, BA, for proof-read the manuscript.

\section{References}

1. Bray F, Ferlay J, Soerjomataram I, Siegel RL, Torre LA Jemal A. Global cancer statistics 2018: GLOBOCAN estimates of incidence and mortality worldwide for 36 cancers in 185 countries. CA Cancer J Clin. 2018;68(6):394-424. https://doi. org/10.3322/caac.21492 PMid:30207593

2. Momenimovahed Z, Salehiniya H. Epidemiological characteristics of and risk factors for breast cancer in the world. Breast Cancer. 2019;11:151-64. https://doi.org/10.2147/bctt. s176070

PMid:31040712

3. Torre LA, Islami F, Siegel RL, Ward EM, Jemal A. Global cancer 
in women: Burden and trends. Cancer Epidemiol Biomarkers Prev. 2017;26(4):444-57. https://doi.org/10.1158/1055-9965. epi-16-0858

\section{PMid:2822343}

4. National Cancer Institute. Cancer Stat Facts: Female Breast Cancer Subtypes; 2020. Available from: https://www.seer. cancer.gov/statfacts/html/breast-subtypes.html. [Last accessed on $2021 \mathrm{Feb} 20]$. https://doi.org/10.32388/7sm165

5. Tan PH, Ellis I, Allison K, Brogi E, Fox SB, Lakhani S, et al. The 2019 World Health Organization classification of tumours of the breast. Histopathology. 2020;77(2):181-5. https://doi. org/10.1111/his. 14091

PMid:32056259

6. Nishimura R, Osako T, Nishiyama $Y$, Nakano M, Fujisue $M$, Toyozumi $\mathrm{Y}$, et al. Evaluation of factors related to late recurrence-later than 10 years after the initial treatment-in primary breast cancer. Oncology. 2013;85(2):100-10. https:// doi.org/10.1159/000353099

PMid:23867253

7. Harahap WA, Nindrea RD. Prognostic Factors of localregional recurrence in patients with operable breast cancer in Asia: A meta-analysis. Open Access Maced J Med Sci. 2019;7(4):690-5. https://doi.org/10.3889/oamjms.2019.151.151 PMid:30894935

8. National Cancer Institute. Breast Hormone Therapy Fact Sheet. Available from: https://www.cancer.gov/types/breast/breasthormone-therapy-fact-sheet. [Last accessed on 2021 Feb 20]. https://doi.org/10.1037/e533512012-001

9. Davey MG, Ryan EJ, McAnena PF, Boland MR, Barry MK, Sweeney $\mathrm{KJ}$, et al. Disease recurrence and oncological outcome of patients treated surgically with curative intent for estrogen receptor positive, lymph node negative breast cancer. Surg Oncol. 2021;37:101531. http://doi.org/10.1016/j. suronc.2021.101531 PMid:33545657

10. Rugo HS, Finn RS, Gelmon K, Joy AA, Harbeck N, Castrellon A, et al. Progression-free survival outcome is independent of objective response in patients with estrogen receptor-positive, human epidermal growth factor receptor 2-negative advanced breast cancer treated with palbociclib plus letrozole compared with letrozole: Analysis from PALOMA-2. Clin Breast Cancer. 2020;20(2):e173-80. https://doi.org/10.1016/j.clbc.2019.08.009 PMid:31836434

11. De-Angelis C, Nagi C, Hoyt CC, Liu L, Roman K, Wang C, et al. Evaluation of the predictive role of tumor immune infiltrate in patients with her2-positive breast cancer treated with neoadjuvant anti-HER2 therapy without chemotherapy. Clin Cancer Res. 2020;26(3):738-45. https://doi.org/10.1158/10780432.ccr-19-1402

PMid:31653641

12. Izci $\mathrm{H}$, Tambuyzer T, Tuand K, Depoorter V, Laenen A, Wildiers H, et al. A systematic review of estimating breast cancer recurrence at the population level with administrative data. J Natl Cancer Inst. 2020;112(10):979-88. https://doi.org/10.1093/jnci/djaa050 PMid:32259259

13. Schunkert EM, Zhao W, Zänker K. Breast cancer recurrence risk assessment: Is non-invasive monitoring an option? Biomed
Hub. 2018;3(3):1-17. https://doi.org/10.1159/000492929 PMid:31988964

14. Lafourcade $A$, His $M$, Baglietto $L$, Boutron-Ruault $M$, Dossus L, Rondeau V, et al. Factors associated with breast cancer recurrences or mortality and dynamic prediction of death using history of cancer recurrences: The French E3N cohort. BMC Cancer. 2018;18(1):171. https://doi.org/10.1186/ s12885-018-4076-4

PMid:29426294

15. Salvo E, Ramirez AO, Cueto J, Law EH, Situ A, Cameron C, et al. Risk of recurrence among patients with HR-positive, HER2negative, early breast cancer receiving adjuvant endocrine therapy: A systematic review and meta-analysis. Breast. 2021;57:5-17. https://doi.org/10.1016/j.breast.2021.02.009 PMid:33677313

16. Van Mackelenbergh MT, Denkert C, Nekljudova V, Karn T, Schem C, Marmé F, et al. Outcome after neoadjuvant chemotherapy in estrogen receptor-positive and progesterone receptor-negative breast cancer patients: A pooled analysis of individual patient data from ten prospectively randomized controlled neoadjuvant trials. Breast Cancer Res Treat. 2018;167(1):59-71. https://doi.org/10.1007/s10549-017-4480-5 PMid:28875243

17. Colleoni $M$, Sun $Z$, Price $K N$, Karlsson $P$, Forbes JF, Thürlimann $B$, et al. Annual hazard rates of recurrence for breast cancer during 24 years of follow-up: Results from the international breast cancer study group trials I to V. J Clin Oncol. 2016;34(9):927-35. https://doi.org/10.1200/jco.2015.62.3504 PMid:26786933

18. Geurts YM, Witteveen A, Bretveld R, Poortmans PM, Sonke GS, Strobbe LJ, et al. Patterns and predictors of first and subsequent recurrence in women with early breast cancer. Breast Cancer Res Treat. 2017;165(3):709-20. https://doi.org/10.1007/ s10549-017-4340-3 PMid:28677011

19. Li Y, Lu S, Zhang Y, Wang S, Liu H. Loco-regional recurrence trend and prognosis in young women with breast cancer according to molecular subtypes: Analysis of 1099 cases. World J Surg Oncol. 2021;19:113. https://doi.org/10.21203/ rs.3.rs-62351/v2

PMid:33849563

20. He XM, Zou DH. The association of young age with local recurrence in women with early-stage breast cancer after breastconserving therapy: A meta-analysis. Sci Rep. 2017;7:11058. https://doi.org/10.1038/s41598-017-10729-9 PMid:28894168

21. Lee MK, Varzi LA, Chung DU, Cao M, Gornbein J, Apple SK, et al. The effect of young age in hormone receptor positive breast cancer. Biomed Res Int. 2015;2015:325715. https://doi. org/10.1155/2015/325715

PMid:26351632

22. Yu NY, Iftimi A, Yau C, Tobin NP, van 't Veer L, Hoadley KA, et al. Assessment of long-term distant recurrence-free survival associated with tamoxifen therapy in postmenopausal patients with luminal a or luminal B breast cancer. JAMA Oncol. 2019;5(9):1304-9. https://doi.org/10.1001/jamaoncol.2019.1856 PMid:31393518 